\title{
Cerebral fat embolism caused by an isolated fracture of a flat bone. Case report and systematic review
}

\author{
E1 Khadi Abdelhak*, Youssef Motiaa, Hicham Sbai and Smael Labib \\ Intensive care unit, Mohamed V hospital, Faculty of Medicine and Pharmacy-tangier, University of Abdelmalek Essaadi-Tangier, Morocco
}

\begin{abstract}
Fat embolism syndrome is a serious complication of long bone fractures, characterized by respiratory, neurological and mucocutaneous signs, often with respiratory syndrome in the first place, however isolated severe brain syndrome remains exceptional. We report the case of a fat embolism syndrome with a cerebral manifestation only due to a closed fracture of the mandibular bone, a neurological deterioration after a free interval was marked with a normal initial cerebral CT. In the case of any clinical suspicion, magnetic resonance imaging must be performed for confirmation of the diagnosis and an evaluation of the severity.
\end{abstract}

\section{Introduction}

Fat embolism syndrome (FES) is defined by a set of clinical, biological and radiological manifestations following the obstruction of small vessels by lipid droplets [1]. Pulmonary manifestations are often revealing and found in nearly $90 \%$ of cases, often associated with neurological symptoms in most cases [2]. On the other hand, the appearance of a serious isolated brain syndrome without respiratory signs remains exceptional. We report a case of fat embolism with isolated brain syndrome following a displaced fracture of the ascending branch of the left mandibular bone.

\section{Observation}

A 75-year-old patient with no pathological history admitted to the emergency room for cranio-facial trauma following a road accident. The admission examination found: a conscious woman with a score of 15 on the Glasgow coma scale (GCS), equal and reactive pupils without sensory-motor deficit or convulsions, eupneic saturated at $100 \%$ in ambient air, with a tachycardia at 110 beats/min and blood pressure at 150/90 mmHg, cranio-cerebral computed tomography (CT) revealed a displaced fracture of the ascending branch of the left mandible without brain abnormalities requiring surgical management. 20 hours later the patient presented a consciousness disturbance, the examination revealed a GCS at 9 associated with a right hemiparesis with bilateral thoracic and conjunctival petechiae, fever at $38.5^{\circ} \mathrm{C}$. tachycardia at 126 beats/min and blood pressure at $157 / 95 \mathrm{mmHg}$, The head CT scan did not show any abnormality, on the other hand the biology shows anemia at $10 \mathrm{~g} / \mathrm{dl}$ and moderate renal failure (urea at $0.84 \mathrm{~g} / \mathrm{l}$ and serum creatinine at $14.7 \mathrm{mg} / \mathrm{l}$ ), the serum electrolytes was without abnormality, the same thing for the coagulation profile. The lumbar puncture made negative. Following the neurological worsening (GCS to 5), the patient was intubated and put on mechanical ventilation, an Angio-MRI was carried out objectifying: areas in hypersignalin $\mathrm{T} 2$ and diffuse flair periventricular and oval centers with vascular microangiopathy lesions on the upper level and with absence of intraand extra-cerebral hemorrhagic lesion (Figure 1) the evolution was marked by non-improvement, the patient died 15 days later.

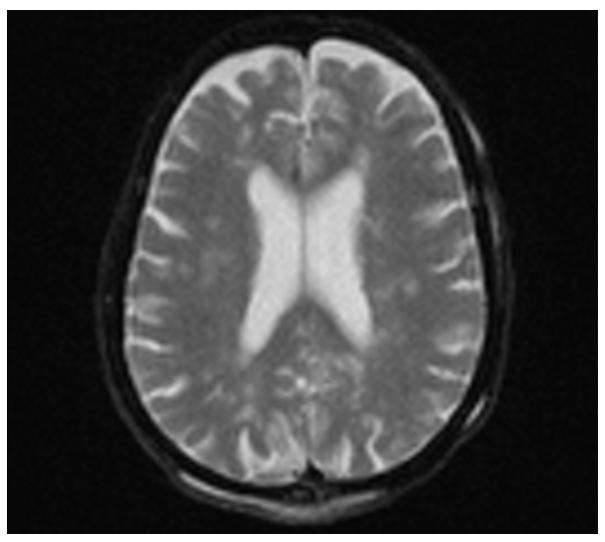

Figure 1. Axial section in $\mathrm{T} 2$ sequence showing periventricular and oval centers hypersignals

\section{Discussion}

The occurrence of a fat embolism also depends on the location and number of fractures. The incidence of fat embolism increases from 0.5$2 \%$ in the case of an isolated fracture of long bone to $5-30 \%$ in the case of multiple fractures including the pelvis [2].

The appearance of a fatty embolism is classically favored by several factors: the association with visceral lesions, the persistence of hypovolemic shock, the extent of the displacement and the lack of immobilization of a fracture site, the prolonged transport and, finally, delayed osteosynthesis [3,4] frequent in our context. On the other hand, the other circumstances of appearance are much more exceptional

${ }^{\star}$ Correspondence to: El Khadi Abdelhak, Intensive care unit, Mohamed V hospital, Faculty of Medicine and Pharmacy-Tangier, University of Abdelmalek Essaadi-Tangier, Morocco, E-mail: elkhadiabdelhak@gmail.com

Key words: cerebral fat embolism, fracture of the mandible, coma, MRI

Received: January 06, 2021; Accepted: January 19, 2021; Published: January 22, 2021 
such: spinal osteosynthesis, blast, hepatic trauma, severe burns, hip or knee arthroplasty or following medical conditions such as: External cardiac massage, intraosseous perfusion, acute osteomyelitis, diabetes and extracorporeal circulation [5].

The etiology and pathogenesis of fat embolism are not always well specified and the pathophysiology of fat embolism is currently poorly understood and still under discussion. There are two theories, one purely physical in which there is embolization of fatty droplets from the bone marrow, the other chemical characterized by instability of lipid emulsions leading to diffuse deposition with damage to the vascular endothelium and activation of coagulation.

Fat embolism syndrome is a disease mainly affecting the capillaries and mainly the venous side. Therefore, the lung is the organ most often affected. However, fatty globules and chylomicron have access to the systemic circulation and can also affect the heart, brain, skin, and retina. The systemic manifestations of FES can be explained by: Arteriovenous pulmonary malformations [6], passage of deformed fatty globules through pulmonary capillaries [7], bypassing pulmonary circulation via a patented foramen ovale $[8,9]$ and reopening of a closed foramen ovale due to an acute increase in pulmonary pressure $[8,10]$.

The complete form of FES is marked by a classic triad associating respiratory distress, neurological disturbance and mucocutaneous petechial syndrome.

Respiratory manifestations are often the first signs to appear observed in more than $90 \%$ of cases, manifested by: tachypnea, dyspnea and hypoxemia, evolving in some cases to respiratory failure requiring mechanical ventilation [11].

Neuropsychic manifestations, observed in $60 \%$ of cases, are the consequence of cerebral systemic emboli and hypoxia [1]. Symptoms may include irritability, anxiety, agitation, confusion, delirium and coma [12], they are only associated with the FES after eliminating another etiology of neurological impairment: traumatic or infectious [13]. The main cutaneous-mucosal manifestation is petechial purpura, which appears between the $2^{\text {nd }}$ and $4^{\text {th }}$ day after the trauma and which can affect up to $60 \%$ of patients [1]. It sits on the anterosuperior part of the thorax, in the neck and armpits, on the oral mucous membranes and the conjunctivae.

A punctate or sparse retinal hemorrhage following the vascular pathways, renal and / or myocardial damage may also be observed [13].

Most cases of cerebral FES presented in the literature are post long bone fractures or associated with flat bone fractures. What is particular for our case is that neurological signs were marked in the foreground following an isolated fracture of a flat bone after a free interval without respiratory manifestations with the presence of bilateral thoracic and conjunctival petechiae.

Routine laboratory examinations are usually marked by thrombocytopenia, of varying intensity, sometimes part of a pattern of disseminated intravenous coagulation; hemolytic anemia is frequent [14]. However, no biological test is specific, the assays of the $C$ reactive protein, the search for intracellular lipid particles in the tracheal samples or in the bronchoalveolar lavage are neither sensitive nor specific [15].

In addition to the clinical elements, imaging is becoming increasingly important in the positive diagnosis of neurological impairment in the GIS, complementing clinical reasoning. Cerebral CT scan, often first-line in a traumatic context, makes it possible to eliminate a hemorrhagic neurosurgical emergency, and sometimes reveals localized hypodensities, diffuse cerebral edema, but in the vast majority of cases, the cerebral CT scan is normal. $[15,16]$.

The MRI then takes all its interest. In the acute stage, diffuse signal anomalies are revealed in the range of blurred or nodular contours of white matter and grey matter in hyposignal in T1-weighted sequences and in hypersignal in T2-weighted sequences. These lesions correspond to pale infarctions. Other hypersignal white matter abnormalities in T1- and T2-weighted sequences have been described and are related to hemorrhagic infarctions [15]. These lesions are mainly located in the subcortical and periventricular white matter, corpus callosum, central gray nuclei, brain stem and cerebellar hemispheres as early as 4 hours after the onset of neurological manifestations. These images correspond to an obstruction of the cerebral microcirculation by the fat emboli, resulting in hemorrhagic necrosis in the neighboring parenchyma [17]. The evolution is towards the persistence of T2-weighted hypersignals of white matter and grey matter corresponding to demyelinating lesions or lacunae, either towards slow and partial resolution or towards total resolution with disappearance of the initial lesions. In the longer term, cortical or cortico-subcortical atrophy may be observed [15].

In our case the initial and control CT returned without abnormality while the MRI showed areas of hyperintensity in T2 and diffuse periventricular Flair and oval centers with lesions of vascular microangiopathy on the upper level with corticosteroid atrophy under cortical.

The diagnosis of fat embolism is primarily clinical, the difficulty of this diagnosis stems on the one hand from the fact that certain manifestations such as hypoxemia or altered consciousness are common in traumatology to other associated lesions, and on the other hand from the transient nature of certain clinical signs. The chronology of symptom onset is evocative, with, in particular, the notion of a free interval. This is of variable duration, ranging from 12 to 36 hours, the shorter the interval, the worse the prognosis [5].

Several criteria have been reported for the positive diagnosis of this syndrome, the Gurd and Wilson classification [18] is widely used (Table 1), for a positive diagnosis of FES, one major and four minor criteria are required.

More recently, a quantitative means of diagnosis of FES has been proposed by Schonfeld [19]. He assigned scores to seven clinical signs - (Table 2), a cumulative score $>5$ is required for a diagnosis of FES.

Our patient meets these criteria, with two major criteria represented by the neurological disorders and petechiae and three minor criteria: tachycardia, fever and anemia with a score of 6 according to Schonfeld.

The diagnosis of SEG remains first and foremost a diagnosis of elimination. In the reported case, secondary neurological deterioration

Table 1. Gurd and Wilson's criteria for the diagnosis of fat embolism syndrome [18]

\begin{tabular}{|l|l|}
\hline Major criteria & Minor criteria \\
\hline Petechiae & Tachycardia $>120$ beats/min \\
\hline Respiratory failure & Fever \\
\hline Neurological disorders & Retinal abnormalities: fat or petechiae \\
\hline & Jaundice \\
\hline & Renal signs: anuria or oliguria \\
\hline & Thrombocytopenia \\
\hline & Anemia \\
\hline & Increased erythrocyte sedimentation rate \\
\hline & Fat macroglobulinemia \\
\hline
\end{tabular}


Table 2. Schonfeld's criteria for the diagnosis of fat embolism syndrome [19]

\begin{tabular}{|l|c|}
\hline Petechiae & $\mathbf{5}$ \\
\hline $\begin{array}{l}\text { Chest x-ray abnormality (Diffuse alveolar } \\
\text { infiltrate) }\end{array}$ & 4 \\
\hline $\begin{array}{l}\text { Hypoxemia } \\
\left(\mathrm{PaO}_{2}<9.3 \mathrm{kPa}\right)\end{array}$ & 3 \\
\hline Fever $\left(38.8^{\circ} \mathrm{C}\right)$ & 1 \\
\hline $\begin{array}{l}\text { Tachycardia } \\
(120 \text { beats } / \mathrm{min})\end{array}$ & 1 \\
\hline $\begin{array}{l}\text { Tachypnea } \\
(30 \text { cycles } / \mathrm{min})\end{array}$ & 1 \\
\hline
\end{tabular}

is for many reasons caused by SEG. Arguments in favor are: displaced flat bone fracture, delayed fracture stabilization, free interval, normal initial brain imaging, skin petechiae, tachycardia, fever and anemia. The Treatment of fat embolism is primarily preventive based essentially on two main points; the first is the early and most complete immobilization of any fracture site, followed by early and definitive surgical fixation. For some, this approach would dramatically decrease the frequency of fatty embolism [20]. The second point is based on the treatment or prevention of hypovolemic shock, stress hypoxia and pain, several drug procedures (infusion of intravenous alcohol, dextran, hypertonic glucose, salicylates, heparin, albumin) have been proposed to reduce the incidence of the syndrome, but none have actually shown any efficacy [21-22].

For Preventive Corticosteroid Use, a Canadian meta-analysis concluded that corticosteroids may help prevent fat embolism and hypoxia, but not mortality in patients who have sustained long bone fractures. However, the authors did not confirm the value of preventive corticosteroid therapy because of the methodological limitations of these trials [23].

The therapeutic management of our patient was purely symptomatic, with maintenance of hematosis and correct blood volume, intubation and ventilation based on neurological criteria.

\section{Conclusion}

The clinical case presented shows the possibility of a severe form of FES with only neurological manifestation following an isolated fracture of a flat bone. This syndrome must be suspected in the presence of an acute alteration of the state of consciousness after a free interval in any patient presenting an orthopedic trauma even of a flat bone. In the face of clinical suspicion, MRI must be performed early, especially in the presence of normal initial brain imaging, it confirms the diagnosis and evaluates the severity of the lesion.

\section{Competing interests}

The authors declare no competing interests with this case.

\section{References}

1. Forster C, Jöhr M, Gebbers JO (2002) Fat embolism and fat embolism syndrome. Forum Med Suisse 28: 673-678.

2. Thicoïpe M, André M, Maurette P, Lassie P, Claverie JP (1988) Post-traumatic cerebra fat embolism. Ann Fr Anesth Reanim 5:418-421. [Crossref]

3. Mimoz O, Incagnoli P, Edouard A, Samii K (1997) Fat embolism syndrome. In: SFAR (Ed) Conférence d'actualisation Paris: SFAR, Elsevier pp: 587-598

4. Bouffard Y, Guillaume C, Perrot D, Delafosse B, Motin J (1984) Post traumatic fat embolism. Ann Fr Anesth Reanim 3: 335-338.

5. Sinha P, Bunker N, Soni N (2010) Fat embolism an update. Curr Anaesth Crit Care 21: $277-281$.

6. Gossling HR, Pellegrini VD Jr (1982) Fat embolism syndrome: A review of the pathophysiology and physiological basis of treatment. Clin Orthop Relat Res 165: 6882. [Crossref]

7. Schemitsch EH, Jain R, Turchin DC, Mullen JB, Byrick RJ, et al. (1997) Pulmonary effects of fixation of a fracture with a plate compared with intramedullary nailing. $J$ Bone Joint Surg Am 330: 642-643.

8. Pell AC, Hughes D, Keating J, Christie J, Busuttil A, et al. (1993) Brief report: Fulminant fat embolism syndrome caused by paradoxical embolism through a patent foramen ovale. $N$ Engl J Med 329: 926-929.

9. Watson AJ (1970) Genesis of fat emboli. J ClinPathol 4: 132-142. [Crossref]

10. Pell AC (1994) Fat embolism syndrome (correspondence). N Engl J Med 330: 642-643.

11. Chhabra B, Kiran S, Senthilnathan TA, Gupta R (2001) Fat embolism syndrome. Ind J Orthop 35: 10-15.

12. Gupta A, Reilly CS (2007) Fat embolism. Cont Edu Anaesth Crit Care Pain 7: 148-151.

13. Adams CB (1971) The retinal manifestations of fat embolism. Injury 2: 221-224.

14. Saigal R, Mittal M, Kansal A, Singh Y, Kolar PR, et al. (2008) Fat embolism syndrome. $J$ Assoc Physicians India 56: 245-249. [Crossref]

15. David H, Rouquette I, Dubayle P, Goasdoue P, Boyer B, et al. (1998) MRI in post traumatic cerebral fat embolism. J Radiol 79: 427-430.

16. Wiel E, Fleyfel M, Onimus J, Godefroy O, Leclerc X, et al. (1997) Cerebral fat embolism after closed trauma to the leg. Ann Fr Anesth Reanim 16: 970-973.

17. Metting Z, Rödiger LA, Regtien JG, van der Naalt J (2009) Delayed coma in head injury: Consider cerebral fat embolism. Clin Neurol Neurosurg 111: 597-600. [Crossref]

18. Gurd AR, Wilson RI (1974) The fat embolism syndrome. J Bone Joint Surg Br 56B 408-416. [Crossref]

19. Schonfeld SA, Ploysongsang Y, DiLisio R, Crissman JD, Miller E, et al. (1983) Fat embolism prophylaxis with corticosteroids. Ann Intern Med 99: 438-443. [Crossref]

20. Riska EB, Millynen P (1982) Fat embolism with multiple injury. J Trauma 22: 891894. [Crossref]

21. Ghatak NR, Zimmerman HM (1971) Cerebral bone marrow embolism. Arch Pathol 92: 112-118. [Crossref]

22. Selig WM, Burhop KE, Malik AB (1987) Role of lipids in bone marrow-induced pulmonary edema. J Appl Physiol 62: 1068-1075. [Crossref]

23. Bederman SS, Bhandari M, McKee MD, Schemitsch EH (2009) Do corticosteroid reduce the risk of fat embolism syndrome in patients with long-bone fractures? A metaanalysis. Can J Surg 52: 386-393. [Crossref]

Copyright: (C2021 Abdelhak EL. This is an open-access article distributed under the terms of the Creative Commons Attribution License, which permits unrestricted use, distribution, and reproduction in any medium, provided the original author and source are credited. 